\title{
Relato de vivência com comunidades ribeirinhas através de mapeamento partici- pativo na floresta nacional de Tefé/AM
}

\author{
Pablo Leandro Proença ${ }^{1}$ \\ ${ }^{1}$ Universidade Federal do Rio Grande do Sul. E-mail: eumundo@ibest.com.br
}

Recebido em 07/2013. Aceito para publicação em 11/2013.

Versão online publicada em 08/11/2013 (http://seer.ufrgs.br/paraonde)

\begin{abstract}
O pescador, ele sai bem cedinho / ele sai bem cedinho, ele vai pescar.
O pescador, ele deixa a Maria / ele deixa os filhos, ele vai pescar.

O pescador, ele ama o rio / ele ama o rio, o Rio Amazonas.

O pescador, ele ama o rio, seus igapós, seus igarapés os seus paranãs e seus lindos lagos.
\end{abstract}

Trecho da Música: “O Pescador”, cantada durante as reuniões.

Enquanto o violão afinava ao som de "O PESCADOR", o balanço do banzeiro ${ }^{1}$ sacudia o barco que levava uma equipe de gaúchos, acompanhados de moradores ribeirinhos e analistas do Instituto Chico Mendes de Conservação da Biodiversidade de Tefé. 0 violão, 0 pandeiro e o chimarrão faziam companhia a um emaranhado de imagens de satélite, lápis de cor, canetinhas hidrocor, lápis de cor, máquina fotográfica, GPS e computadores. Viajando pelos meandros, Paranãs e igarapés da Floresta Nacional de Tefé percorremos, junto com as comunidades que ai vivem, os territórios, paisagens e histórias de vida dos tantos moradores que dependem da floresta e das águas. 0 barulho do barco dava a trilha sonora da paisagem. Como numa tela de cinema nos entretínhamos o dia inteiro assistindo Samaúmas, Castanheiras, Buritizeiros, Jatobazeiros, Ingazeiros de todos os tamanhos; o Japó, meio negro meio amarelo, cantava nos seus ninhos que pareciam gotas caindo das árvores de castanha e os macacos-prego balançavam os galhos na mata em busca de frutas, enquanto víamos troncos flutuando ao longe, que na verdade, não eram troncos, mas os Jacarés, desconfiados de tantos gaúchos com seu chimarrão em terras amazônicas. Desconfiança cheia de razão, afinal gaúcho em terras amazônicas, nunca foi sinal de preservação.

Mas antes de sacudir nas águas do médio Solimões, o banzeiro sacudiu na região das águas do Guaíba. Recebemos o convite (desafio) do ICMBio de Tefé no inicio de 2012, ao Núcleo de Estudos Geografia e Ambiente (NEGA/UFRGS), para participar da elaboração do plano de manejo da FLONA de Tefé no Amazonas, unidade de conservação federal com 1.020 .000 hectares, localizada no médio Rio Solimões nas cidades de
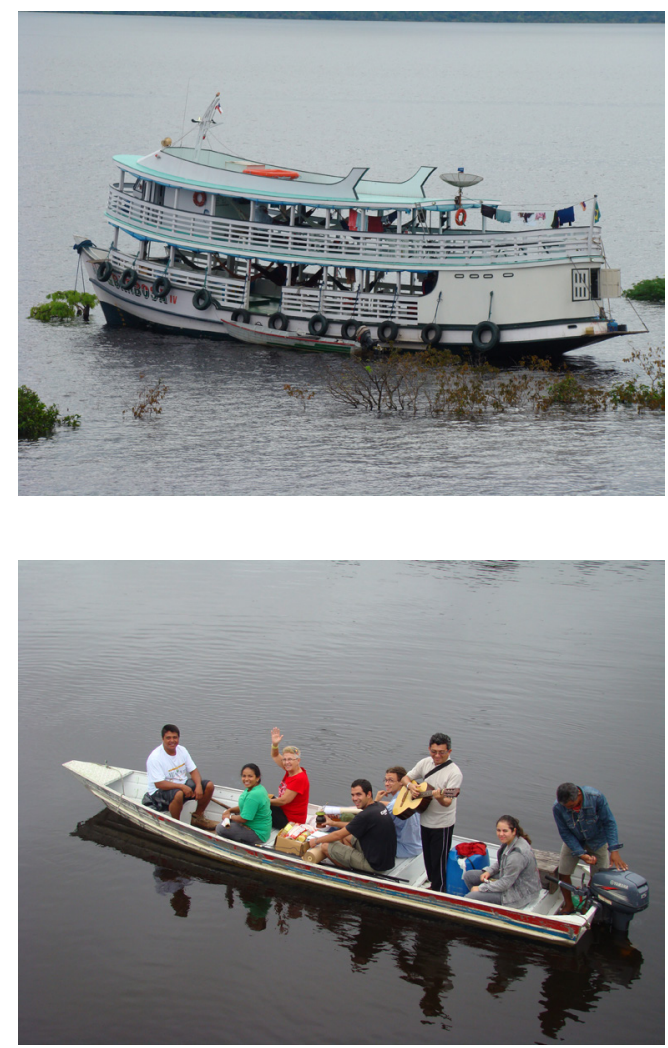

Barco Almirante Barbosa (mais acima) e a Voadeira (embaixo). Transporte da equipe para as comunidades durante o processo de mapeamento. A voadeira carregava a equipe pelos igarapés e caminhos mais estreitos e pouco profundos.

Tefé, Alvarães, Carauari e Juruá. 0 movimento gerou empolgação, envolvimento, diálogos, debates e muito trabalho. 0 medo do jacaré, das cobras, da malária, da contaminação da água acompanhava as discussões e brincadeiras no desenrolar dos primeiros passos do projeto. Coordenar um processo de mapeamento par-

${ }^{1}$ Ondulação das águas provocada por outras embarcações ou pelo vento. 
ticipativo, com comunidades ribeirinhas do médio Rio Solimões, uma região completamente desconhecida pela equipe de geógrafas e geógrafos, não seria uma tarefa a que estávamos acostumados na academia. Pelo contrário, mostrou-se um enorme desafio, pois além de desconhecedores da realidade da Amazônia profunda, era o primeiro trabalho do núcleo com mapeamento participativo, em uma unidade de conservação no Amazonas.

Antes de irmos para a floresta necessitávamos gerar alguns produtos que seriam fundamentais para o mapeamento, como:

- Imagens de satélite da área da FLONA, recortadas do Google Earth;

- Dados sócio econômicos sobre a FLONA para familiarizarmos com a região;

- Oficina de introdução ao ARCGis onde trabalharíamos os mapas;

O objetivo central do trabalho de mapeamento foi, junto com os ribeirinhos e ICMBio de Tefé realizar um levantamento dos territórios utilizados pelas comunidades para pesca, caça, plantio, extrativismo, preservação; os nomes dos lagos, igarapés e Paranãs por eles utilizados; além da rotina diária e da produção dos homens e mulheres que vivem na beira dos igarapés, rios e lagos que compõem a FLONA de Tefé. Ou seja, "seu Raimundo, mostra pra gente aqui nesta imagem de satélite onde o senhor pesca... Jucelino, onde estão localizados os castanhais e lagos com pirarucu que a tua comunidade utiliza?... Elias e Tabita, esta farinha bem amarelinha, que comemos no almoço, extraída da mandioca que vocês plantam, aonde é cultivada?..." E enquanto as carapanãs ${ }^{2}$ voavam ao redor da gente buscando seu alimento, a mãe gritava: "ô menino deixa de enxerimento!" Íamos aprendendo sobre o território dos ribeirinhos e sua forma de vida.

Realizamos duas expedições de dez dias cada, viajando pelos rios Tefé, Curumitá e Bauana parando

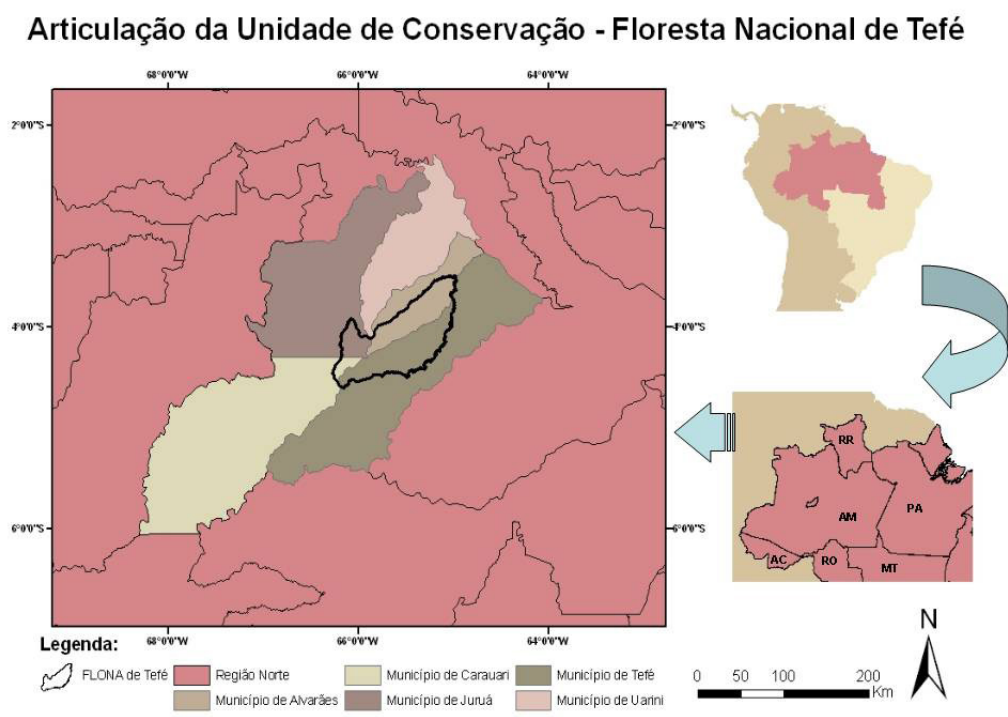

Localização da Floresta Nacional de Tefé.

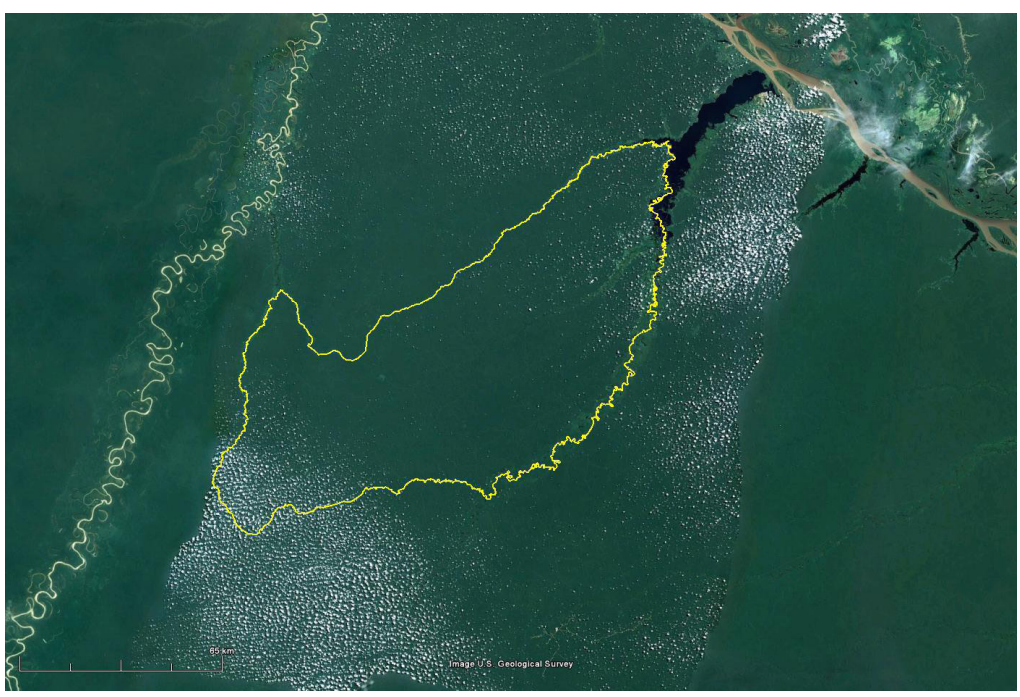

Imagem de satélite marcando em amarelo o limite da FLONA; no canto superior direito o Rio Solimões. FONTE: Google Earth

\footnotetext{
${ }^{2}$ Nome regional dado para um tipo de Mosquito.
} 
em comunidades específicas que abrangiam setores, e realizando reuniões com os ribeirinhos. Cantamos músicas, ouvimos piadas e apresentações culturais dos comunitários. 0 método utilizado foi agrupar cada comunidade do setor em que estávamos e, escrever, desenhar, pintar as informações em uma imagem de satélite do programa Google Earth de tamanho A0 utilizando um papel vegetal sobreposto à imagem. Cada comunidade foi delineando seus territórios, seus locais de sustento e trabalho, os igarapés, sacados, ressacas e lagos que mais utilizavam. As crianças, curiosas com tanta gente estranha, nos ofereciam todo seu carinho, alguns presentes e sorrisos tímidos. Com olhos pretinhos como o açaí, rodeavam as reuniões sempre em grande número, no colo de suas mães, saindo e entrando, pulando e dançando roda com seus irmãos da comunidade, cheios de pavulagem ${ }^{3}$.

\section{EXPEDIÇÃO - "Amazônia: Pátria das águas”}

Chegamos à cidade de Tefé e logo percebemos que a vida ali era delineada pela relação com as águas. 0 porto da cidade estava cheio de barcos grandes, lanchas e pequenas canoas com motor de popa, chamadas de rabeta. Estes fazem a ligação entre as cidades grandes e médias da região e as comunidades que se localizam na lindeira dos rios e igarapés. 0 deslocamento na região era realizado prioritariamente pelas águas. Os alimentos comercializados no mercado da cidade em grande parte são derivados da mata e dos roçados da região, como o açaí, tucumã, farinha, peixe, macaxeira, banana, abacate, maxixe, castanha, etc. Algumas características da vida amazonense foram bem perceptíveis na chegada a Tefé.

Após o primeiro contato com a cidade, embarcamos no barco Almirante Barbosa que seguiu o caminho líquido rumo às comunidades, adentrando pelo lago de Tefé em direção ao rio Tefé, Curumitá e Bauana. Ao longo da viajem até a primeira comunidade realizamos reuniões, discussões com ICMBio e Comunitários que estavam acompanhando, para refinar o trabalho de mapeamento, organização dos mapas e do material que seria utilizado nas reuniões.

A primeira expedição de mapeamento participativo, que carinhosamente chamamos de: "Amazônia: Pátria das águas" aconteceu no mês de maio, época das cheias dos rios no Amazonas. Momento do ano em que o plantio e a caça ficam difíceis na várzea. No entanto, a imensidão de água faz com que o horizonte líquido quase se junte com o horizonte vegetal, ou seja, chega o momento em que o que separa as águas do céu é uma linha fina de vegetação, e em alguns lugares esta linha não existe. As praias desaparecem, os barcos estacionam na porta das casas, formam-se ilhas de vegetação e o volume de água permite que os barcos grandes viajem com maior segurança, maior rapidez por caminhos mais curtos. 0 peixe ocupa uma área maior, está mais
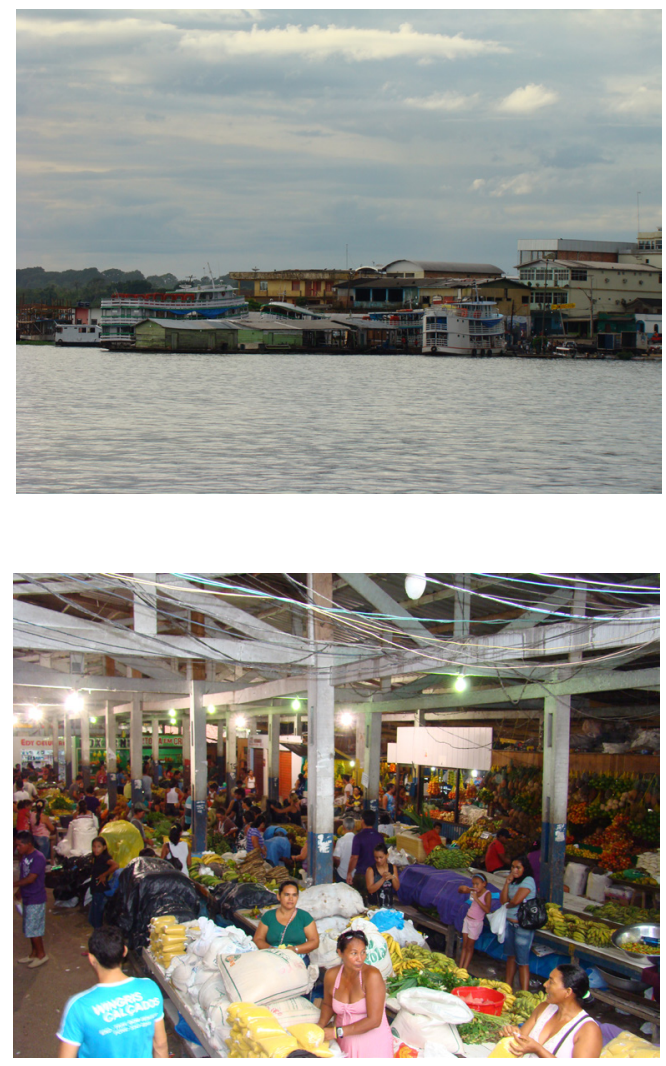

Mais acima o Porto de Tefé e embaixo o mercado municipal.

disperso, mas isto não é empecilho para a pesca que fornece o alimento básico do ribeirinho do amazonas: tambaqui, pirapitinga, pacu e muitos outros. Uma quantidade gigantesca de água orquestra a vida dos ribeirinhos neste período do ano.
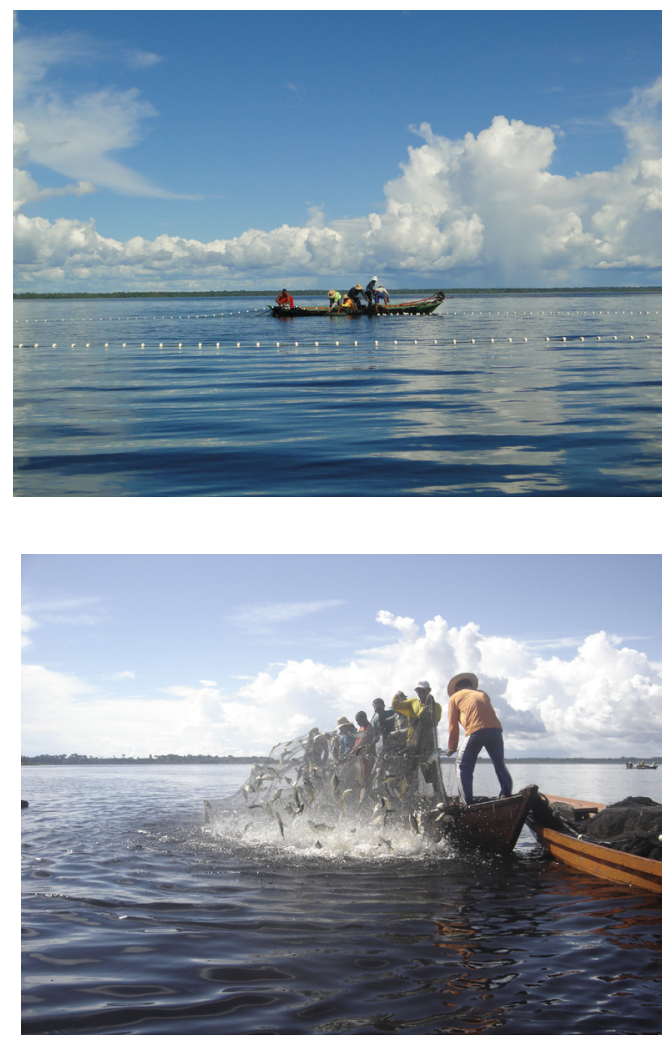

Pesca na cheia. Onde o horizonte das águas quase toca o horizonte da vegetação e se junta com o céu. 

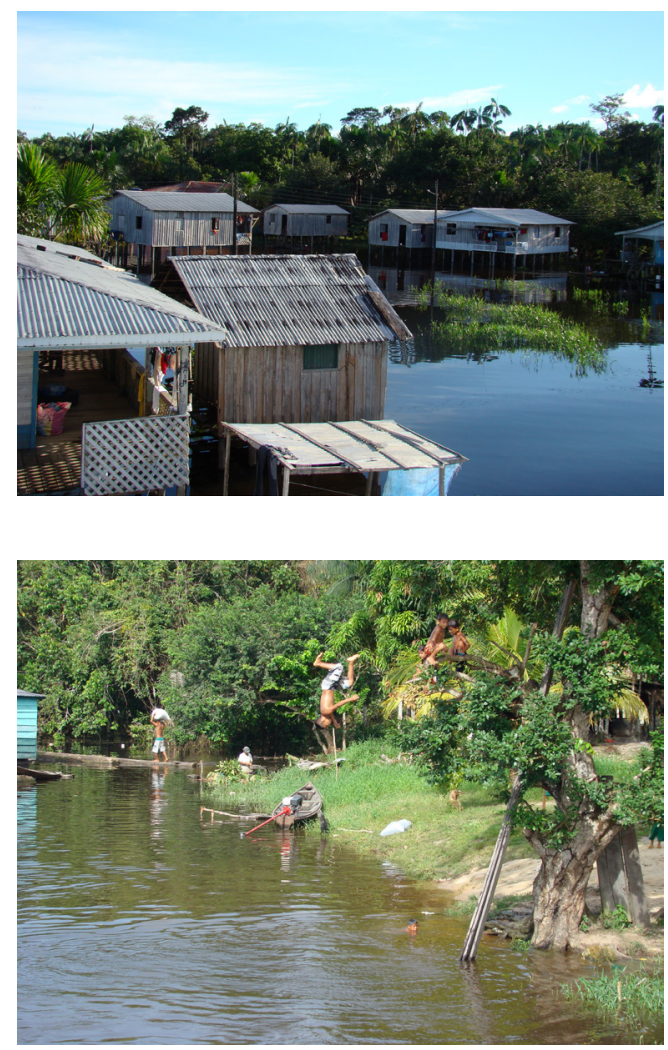

Casas dentro d'água e as crianças pulando das árvores na água.

A primeira parada foi na comunidade Itaúba, no setor Alto rio Tefé que agrega nove comunidades ribeirinhas. Na escola da comunidade foi realizada a primeira reunião e o mapeamento das informações. No primeiro momento foi feita a apresentação do grupo, com os objetivos do trabalho. 0 segundo momento foi o mapeamento das informações que os ribeirinhos iam relatando, superpostas em papel vegetal sobre uma imagem de satélite. Este processo aconteceu em dezessete cortes de imagens de satélite, que traziam as áreas de cada comunidade da FLONA. 0 processo de mapeamento foi realizado pela manhã, com as informações dos lugares de pesca, caça, extrativismo, roçado e finalizado na parte da tarde com os dados dos ciclos da produção, anual e diário. Em geral almoçamos com as comunidades, o que nos permitiu ouvir as histórias de vida, conversar com as mulheres, crianças e os homens anciãos das comunidades. Estar mais próximo da forma de vida e entender através dos olhos e das palavras deles a relação com a floresta.

Após a reunião no alto rio Tefé as reuniões de mapeamento seguiram nas comunidades abaixo que representaram os outros seis setores da FLONA:

- Paxiubinha, no setor Médio Rio Tefé;

- Boa Vista do Curumitá, no setor Boa vista no rio Curumitá;

- Bom Jesus, setor baixo Tefé;

- São Francisco, setor rio Bauana;

- São Francisco do Arraia, no Lago Tefé.

Além das reuniões que aconteceram nas seis comunidades houve momentos de visitas a outras três para ver o roçado, a produção da farinha, conversar com os comunitários, visitar suas casas e as escolas.
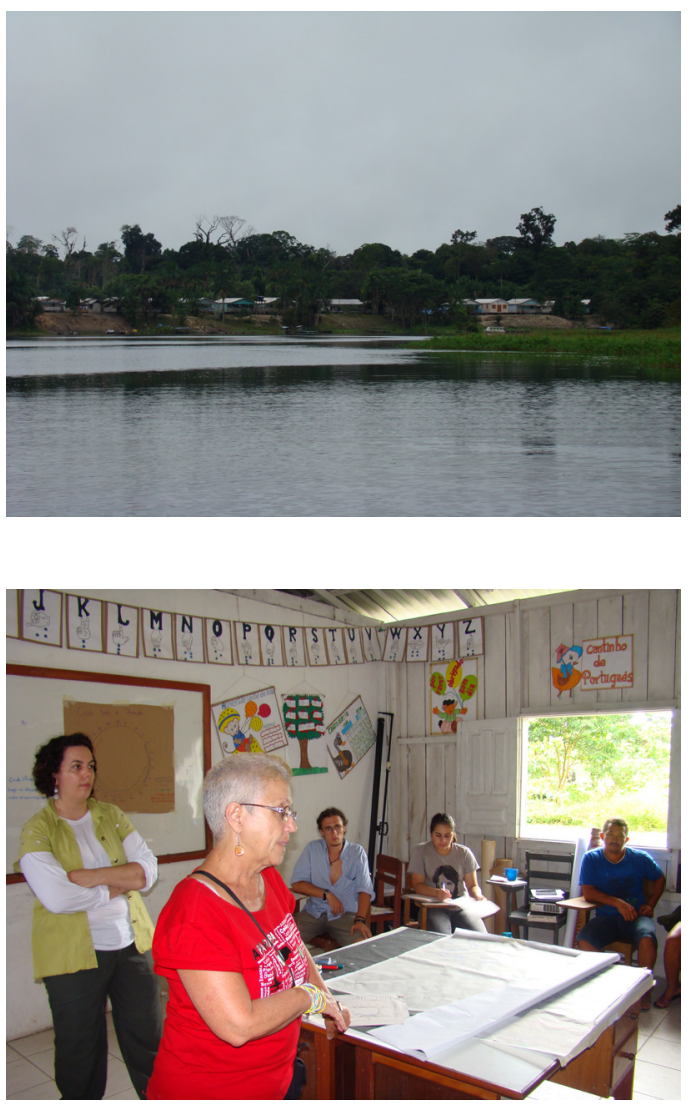

Vista da comunidade Itaúba e apresentação do trabalho de mapeamento.
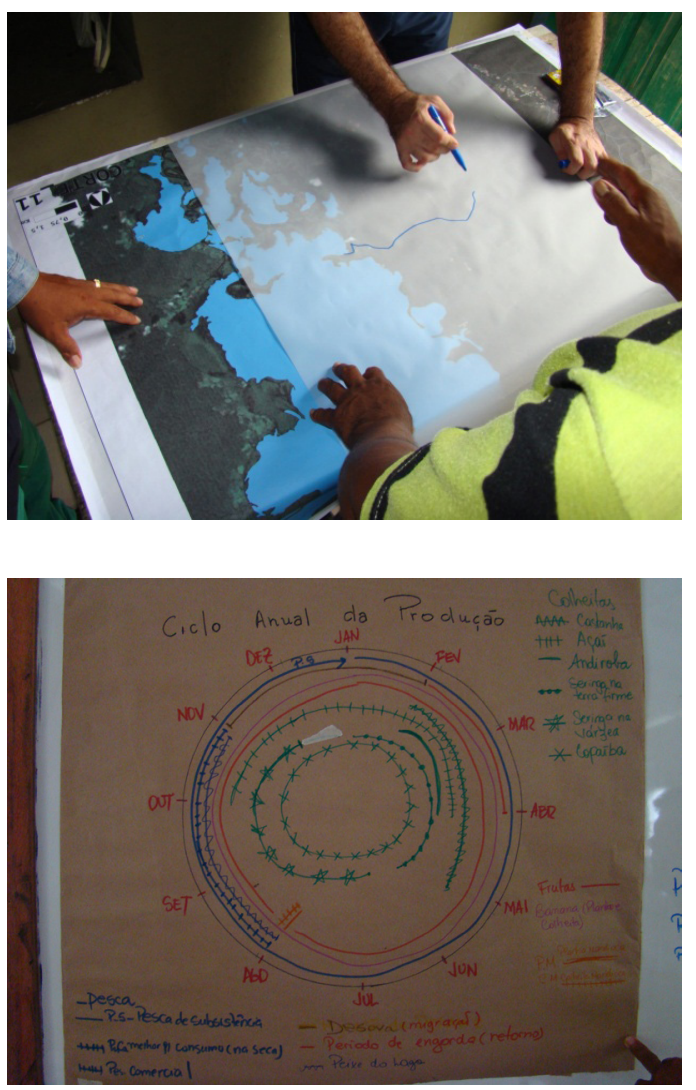

Mapeamento das informações e coleta de dados do ciclo anual da produção.

O primeiro trabalho de campo foi assim. Levantamos os dados, colhemos informações, aprendemos as canções, as expressões, formas de falar, "entendemos" um pouco dos conflitos, da história de ocupação da re- 
gião e da história de vida de cada comunidade. Aprendemos quanto à capacidade dos ribeirinhos, de localização nas imagens de satélite e o conhecimento a cerca do seu território, pois estes não só entendiam as imagens de satélite bem, mas se localizavam perfeitamente. Além disto, as crianças buscavam sempre mostrar-nos algo, uma fruta, uma dança, uma brincadeira. Ou seja, mostrar suas capacidades, seus entendimentos de mundo para os visitantes que vinham de longe.
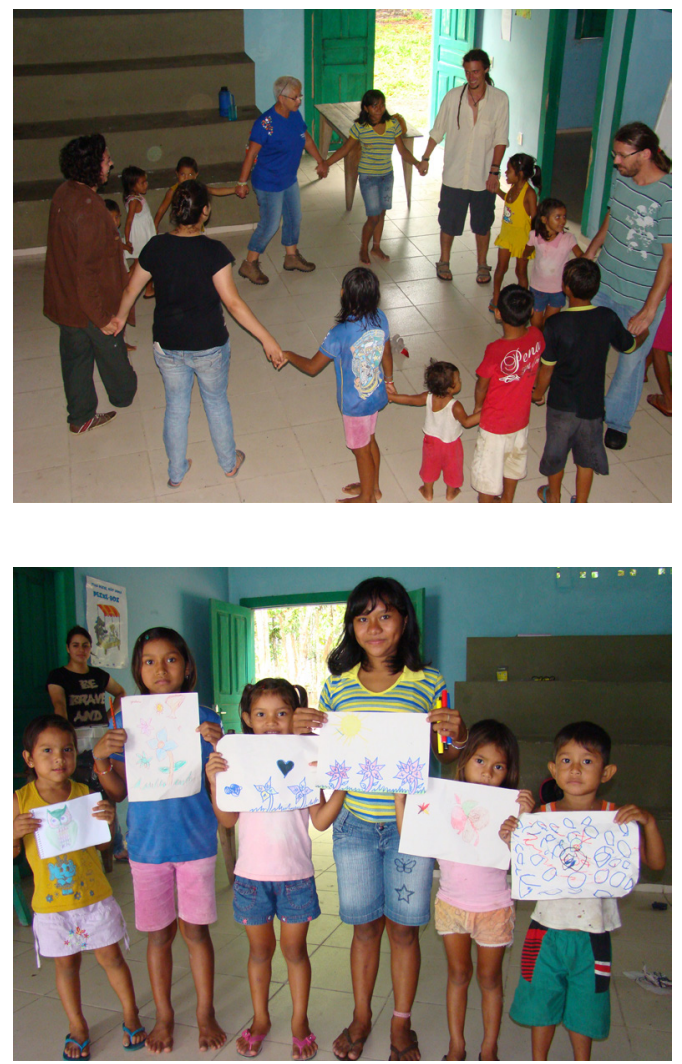

Atividades com as crianças das comunidades.

\section{PERÍODO ENTRE EXPEDIÇÕES}

Após a profundidade da primeira vivência e mapeamento voltamos mais de cinco mil quilômetros no espaço. Ao lugar de origem, refletir, trabalhar, sistematizar, discutir, conflitar. 0 primeiro grupo contou as histórias e os "causos" acontecidos na vivência do mapeamento participativo dos dez dias com comunidades ribeirinhas da região do médio Solimões. Mas principalmente agrupamos as informações em mapas elaborados no programa ARCGis, tudo que foi registrado em campo, passou pelo olhar e pelo trabalho intenso de uma equipe grande de geógrafos e estudantes de geografia. Elaboramos mapas de hidrografia com os nomes adotados pelos comunitários para definir os corpos e cursos d'água; agrupamos as informações sobre extrativismos de castanha, açaí, bacaba, buriti, pupunha,...; Sobre o roçado; sobre a pesca; a caça; o ciclo de trabalho e da produção, diários e anual. Discutimos as legendas, debatemos, idealizamos, enfim, preparando os primeiros resultados para a segunda expedição que se realizou no mês de agosto.
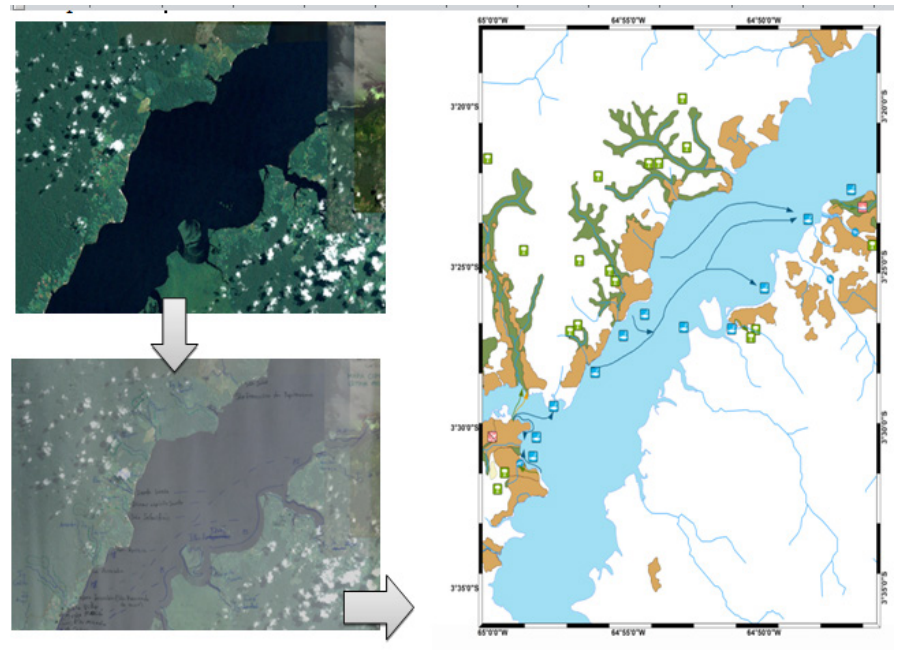

Imagem de satélite (canto superior esquerdo). Sobre ela o papel vegetal onde eram rabiscadas as informações e por último (à direita) o mapa parcial com o resumo das informações.

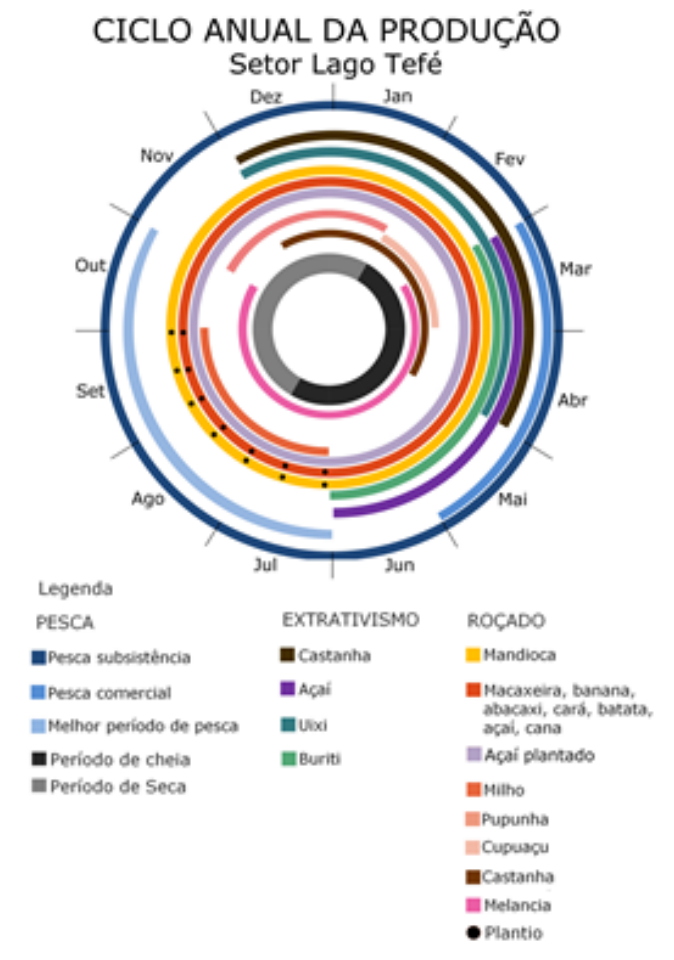

Sistematização das informações coletadas na primeira expedição. Ciclo Anual da Produção no setor Lago Tefé.

No tempo entre a primeira e a segunda expedição, sempre dialogando com o ICMBio de Tefé, trabalhamos intensamente, fomos buscando entender a realidade que estávamos nos envolvendo. Preparando os mapas, os ciclos, a cabeça e o coração para voltarmos a Tefé. 0 ICMBio demandava algumas informações para o mapeamento e, assim, fomos encaminhando o trabalho.

\section{EXPEDIÇÃo - "Caboquinho: Filhos do Amazonas"}

Saímos de Tefé ainda noite. 0 sol nem havia se mostrado, mas o calor do Amazonas já nos acompanhava. Vimos o nascer do sol de dentro do barco, sol que saia de dentro das águas para clarear a vida. E voltamos no dia 06 de agosto de 2012, com a expedição chamada: "Caboquinho: Filhos do Amazonas", com a equipe 
maior ainda, com alguns cortes de imagens de satélite e os mapas elaborados, produto parcial do primeiro mapeamento; lápis de cor, giz de ceira e papel, computadores, GPS pois desta vez pensamos uma atenção especial para com as crianças das comunidades. Subimos o rio Tefé, assistindo ao vivo a paisagem, com o céu azul refletido nas águas escuras do lago. Passamos por muitas comunidades no caminho, e dali as pessoas vinham na beira nos saudar com olhares curiosos. Fomos em direção à comunidade Itaúba, setor Alto rio Tefé onde chegamos apenas de vodeira por um Caminho estreito; depois até Comunidade São Francisco da Ponta da Sorva, no setor médio Rio Tefé; nas comunidades Boa Vista, no setor Boa vista do rio Curumitá e na comunidade do Estirão, setor São Sebastião do Rio Curumitá; no São João do Miriti, setor Bauana; e no São Raimundo de Cima, no Lago Tefé.

No caminho realizamos reuniões discutindo, organizando a coordenação das atividades e o material que iríamos utilizar. Nosso objetivo foi apresentar os resultados do primeiro mapeamento que seria avaliado e complementado pelas comunidades ribeirinhas, além de incluir no mapeamento, aquelas comunidades que não se fizeram presentes na primeira expedição. $\mathrm{Ou}$ seja, se o que resultou do primeiro mapeamento estava realmente condizente com a realidade das comunidades, se a linguagem estava clara, se os nomes, definições, legenda e localizações estavam corretos.

O ICMBio coordenou na parte da tarde uma discussão sobre o acordo de gestão, que tratava das regras e do uso da FLONA, entre as comunidades e dentro da própria comunidade dos ribeirinhos. Tudo o que era ou não era permitido na FLONA partia dos próprios comunitários. Discutimos com eles se estavam de acordo, se necessitavam complementar ou retirar algumas ideias que estavam na proposta inicial. Também conversamos sobre a proposta de zoneamento da FLONA, que discutia a divisão da unidade de conservação em:

- Zona populacional - área de concentração das comunidades;

- Uso comunitário - áreas utilizadas pelas comunidades;

- Preservação - áreas a serem preservadas, sem nenhum uso;

- Amortecimento - áreas ao redor da FLONA.

Esta demanda do ICMBio que também partiu das próprias comunidades permitiu-nos ter uma ideia maior da relação de uso do território pelos ribeirinhos, assim como dos conflitos existentes. Com chimarrão e bolacha e umas piadas as reuniões eram sempre descontraídas. As reuniões aconteciam nas escolas, que estavam sempre abertas, e igrejas, os espaços de reunião das comunidades.

Paralelo ao trabalho da tarde foram levantadas informações a cerca dos principais conflitos, principais demandas e as principais possibilidade de ampliação das atividades econômicas das comunidades. Através de um quadro-síntese com informações de cada comu-
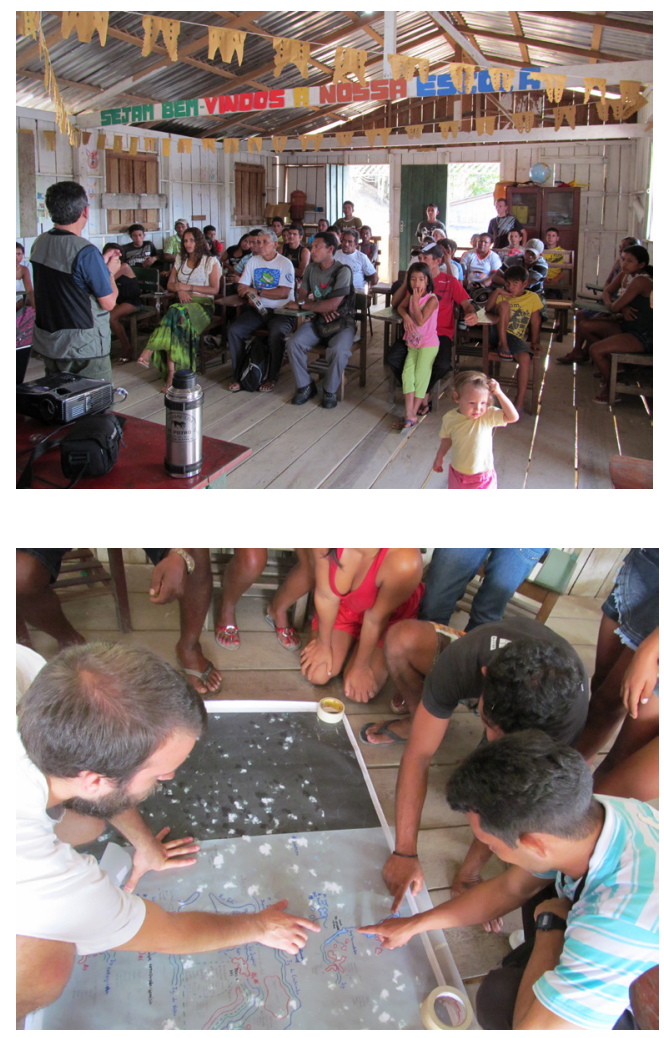

Reunião na escola e conferência das informações.
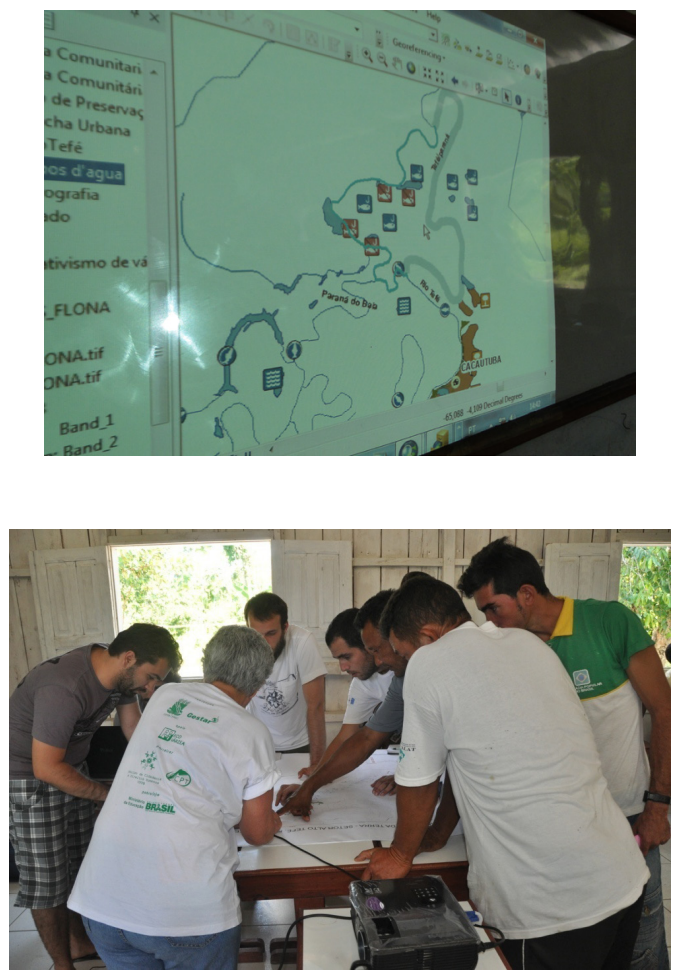

Apresentação e discussão dos resultados do primeiro mapeamento.

nidade presente nas reuniões levantamos as atividades econômicas, e os conflitos derivados destas atividades, como por exemplo a pesca, realizada em lugares proibidos ou por invasões em áreas de outras comunidades; assim como os tipos de atividades que os ribeirinhos gostariam de desenvolver em forma de complementação às atividades econômicas já existentes. Cada comunidade foi apontando seus conflitos, inclusive no mapa, em forma de pontos vermelhos. Também as demandas 
sociais, de qualidade de vida foram apontadas pelos ribeirinhos, com atenção para melhoria da Educação, extremamente precária como pudemos observar na FLONA; da energia, saneamento, saúde e violência.

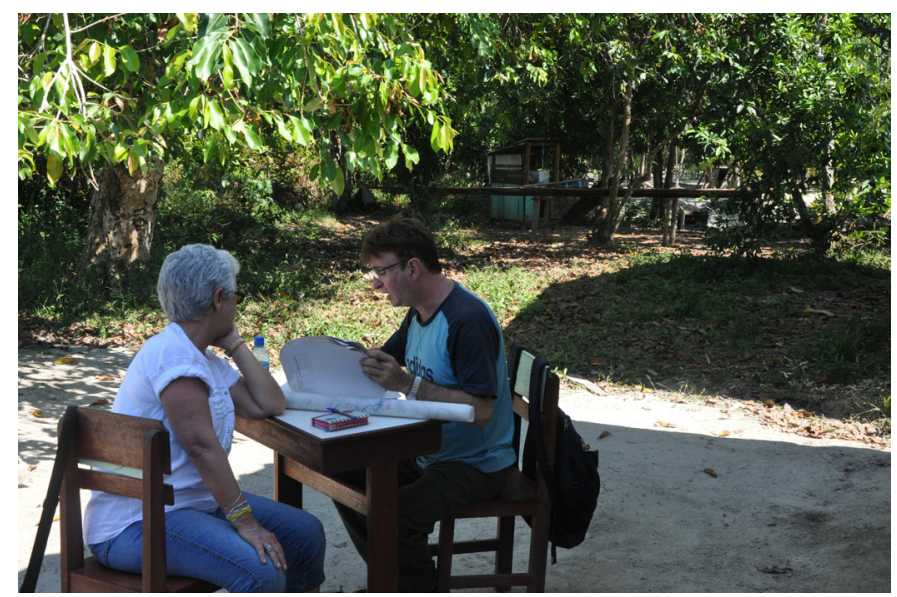

Organização do levantamento dos conflitos

Outro trabalho gerado pelas expedições e aprofundado na segunda foi o estudo da condição alimentar da população ribeirinha da Floresta Nacional de Tefé. Na primeira expedição houve uma introdução ao tema, através de conversas mais informais sobre os hábitos praticados, o peixe, a farinha, o açaí pudemos ver de perto o que era a alimentação deles durante os dez dias da expedição. Já na segunda expedição, sentimos a necessidade de fazer um levantamento estruturado das informações sobre a alimentação. Isto se deu através de entrevistas semiestruturadas tendo as mulheres como foco, pois entendíamos que elas são as diretamente envolvidas na alimentação das comunidades, mesmo sendo a pesca e o plantio uma atividade majoritariamente realizada pelos homens. E os resultados das entrevistas trouxeram como base da alimentação a Farinha oriunda da mandioca e o peixe, juntamente com pequenos animais criados nos quintais das casas (patos, galinha), produtos da alimentação o ano inteiro. Apontaram o açaí como uma referência alimentar, porém sazonal juntamente com outros produtos derivados da floresta como a caça, o buriti, a bacaba, o abacate, etc. Neste processo, questionamos sobre a relevância dos programas sociais (bolsa família, bolsa verde), sendo que as mulheres indicaram sua grande importância para mantimento da alimentação, no entanto, sendo insuficiente para dar conta das demandas.

Nesta expedição chegamos no limite da navegabilidade nos rios da FLONA, pois dali a algumas semanas as águas já estariam tão baixas que seria impossível viajar de barco grande. A marca das águas na vegetação era bem visível, já não estavam tão próximos os horizontes vegetais e líquidos e começavam a aparecer praias nas margens das comunidades. As águas estavam em um novo ciclo, os lagos começavam a aparecer e os peixes ficavam limitados no espaço. Os barcos e canoas ficavam mais distantes quanto mais a água se afastava das portas das casas, trazendo mais trabalho pa-

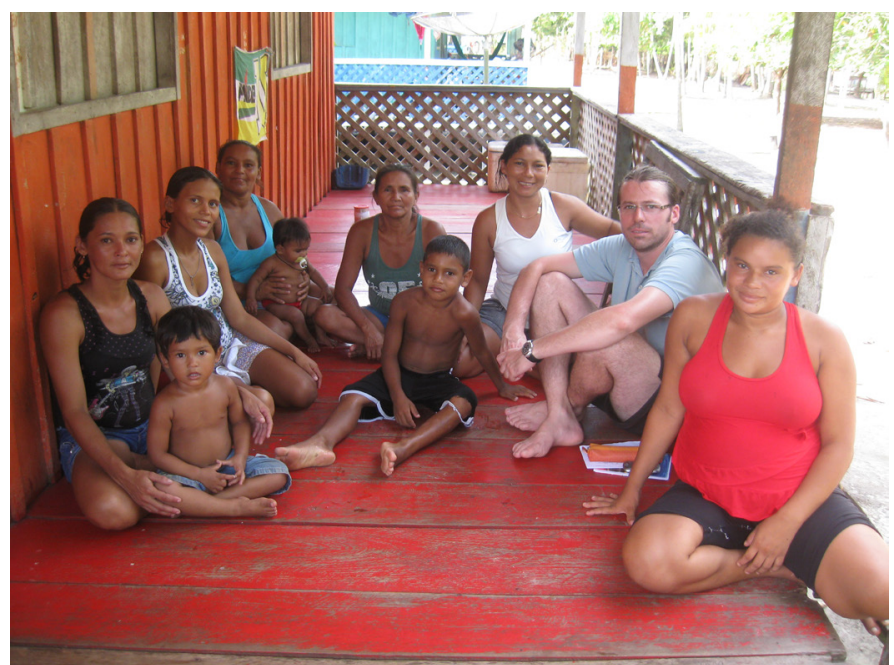

Reunião de levantamento das informações de alimentação com as mulheres da FLONA.
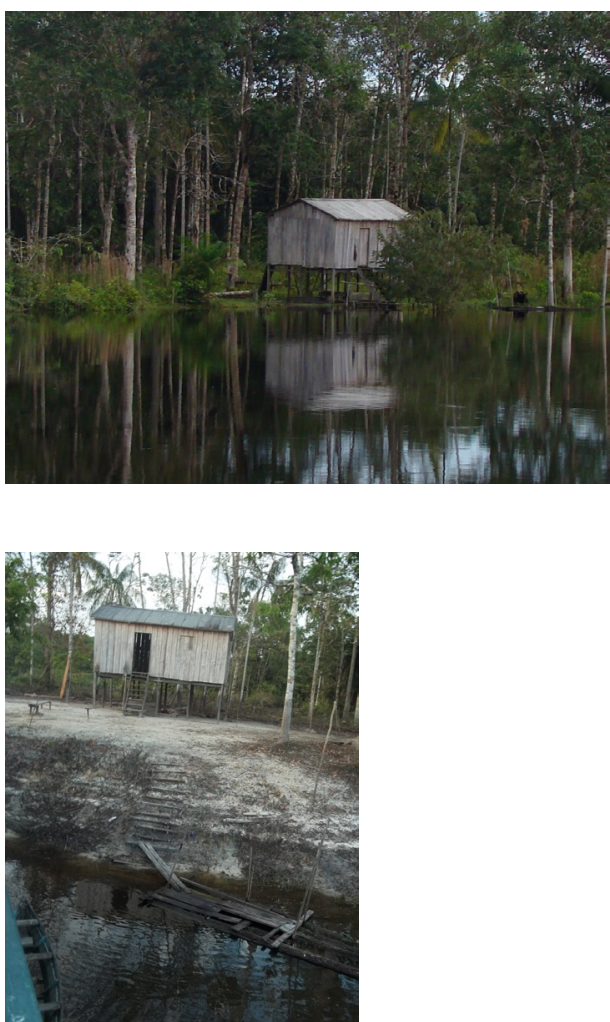

A mesma casa no momento da cheia e da vazante.

ra os ribeirinhos, pois estes carregavam sua produção cada vez mais longe. Furos e paranãs já não comportavam mais grandes embarcações, mas os caminhos por terra, ou varadouros ficavam acessíveis. Era possível ver os peixes pulando nas margens de terra, e os jacarés esperando pela refeição. Estava na época de iniciar o plantio da mandioca na várzea e esperar pela próxima cheia.

Enquanto aconteciam as reuniões com os comunitários as crianças pintavam e desenhavam em outro espaço, brincavam de roda e cantavam música, sempre acompanhadas por alguém da equipe de mapeamento. Bichos, árvores e casas, figuras humanas, helicóptero, barcos grandes revelavam a realidade e as conexões diárias que as crianças viviam nas suas comunidades. 

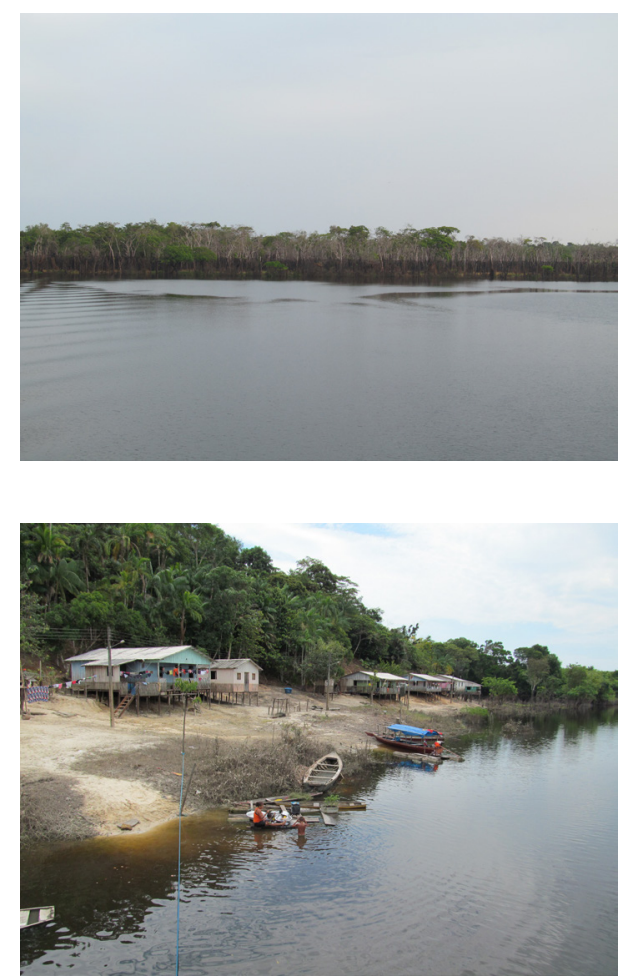

Marca escura da água na vegetação (à esquerda) e marca da água nas casas.
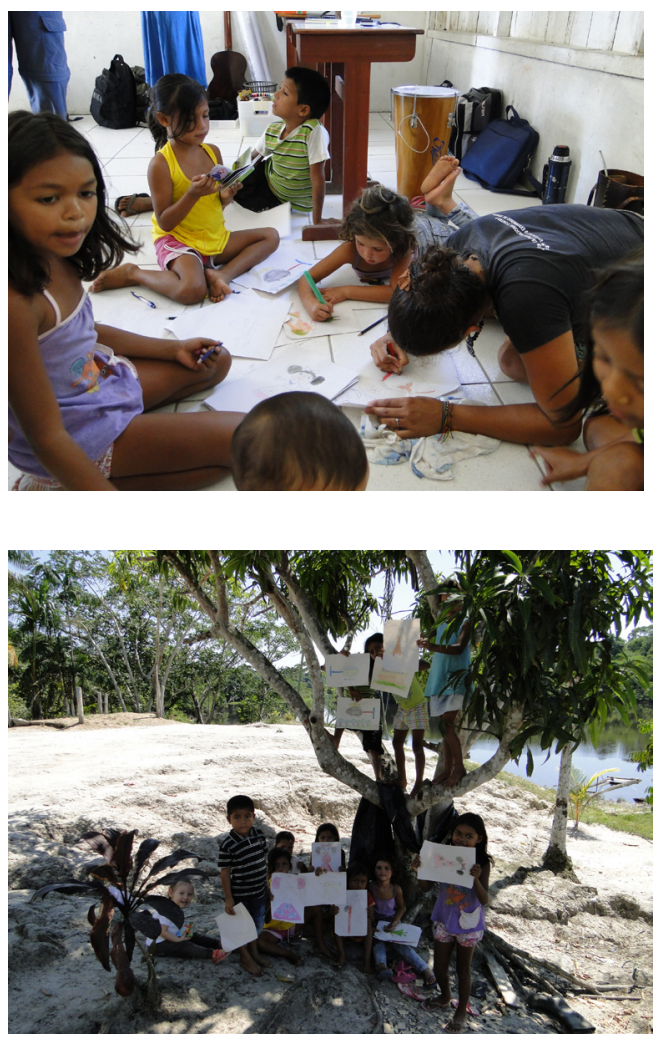

Atividade de pintura e desenho com as crianças.

Neste caminho líquido, a relação não se deu na forma pesquisador versus objeto de pesquisa, não havia objeto de pesquisa, senão protagonistas da construção de uma gestão participativa em uma unidade de conservação. A relação foi de amizade profunda com os comunitários, com as famílias, mas principalmente com as crianças que nos adotaram sem medos. Em principio tínhamos uma grande preocupação com a forma do che-
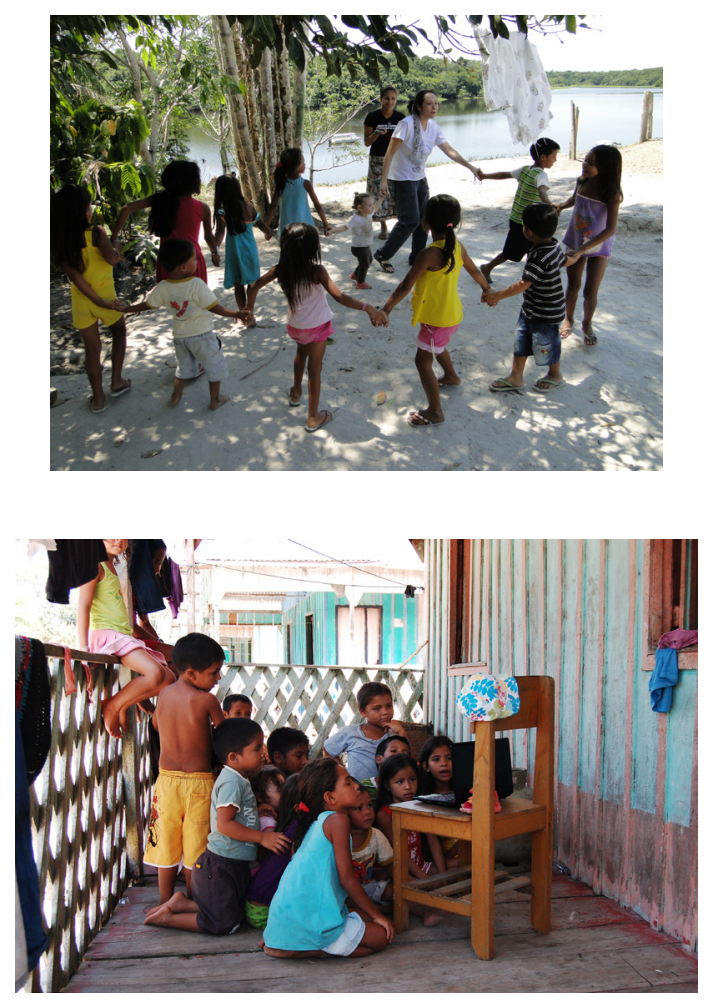

Brincadeira e filme animado

gar" nas comunidades, como falar, como agir, como levar o trabalho, no entanto a extrema receptividade colocou de lado todo polimento e preocupação com esta forma do chegar. Nossa "experiência" acadêmica foi guiada pela sensibilidade da vivência no momento, nas comunidades, na floresta. Sentir que era necessário dar atenção para as crianças no meio da reunião, que era necessário andar de pés descalços e sentar misturados pela sala com os comunitários, não como algo pensado, mas como algo fluido.

Conversamos muito com os ribeirinhos nos momentos sem reunião. Visitamos seus locais de trabalho, de lazer, suas casas, sempre com a permissão deles e por sua receptividade. Eles tinham muita vontade de mostrar sua forma de vida, como trabalhavam sua cultura e a profundidade de suas histórias. Situações como, por exemplo: por não possuírem água encanada lavam a louça (nas comunidades ribeirinhas é chamada de vasilha) e tomam banho na beira dos rios, igarapés e lagos, usando a água que necessitam. Para as crianças é uma forma de diversão pular e nadar na beira na hora do banho. Isto permite uma relação intensa com a água, e em todas as comunidades que visitamos, dificilmente encontramos pessoas que não sabiam nadar ou que tinham medo da água. Aprendemos um pouco das medicinas naturais da mata e a forma como eles tratam e previnem a Malária, grande problema na floresta Amazônica. 0 sangue é coletado da pessoa que tem sintomas da doença e em um dia, já é possível receber a confirmação. 0 peixe assado e a farinha de mandioca são os alimentos básicos do ribeirinho do amazonas. A abundância dos peixes nos rios e a falta de energia para armazenamento permite que as comunidades estejam sempre pescando, sempre trazendo peixe fresco. Algu- 
mas vezes utilizam o Paneiro para o peixe outras para carregar a Mandioca.
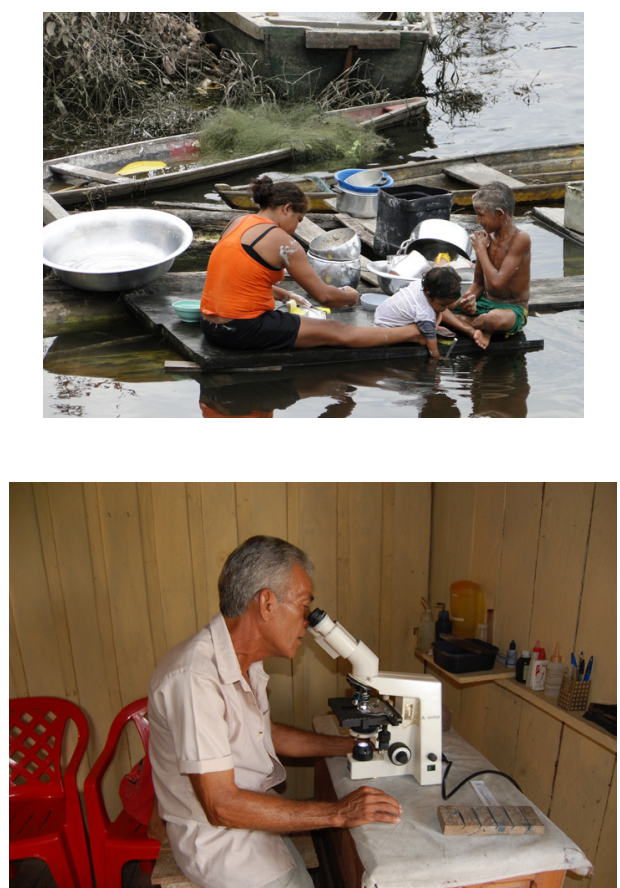

Ribeirinha lavando as vasilhas e embaixo, análise feita nas comunidades para detectar Malária.
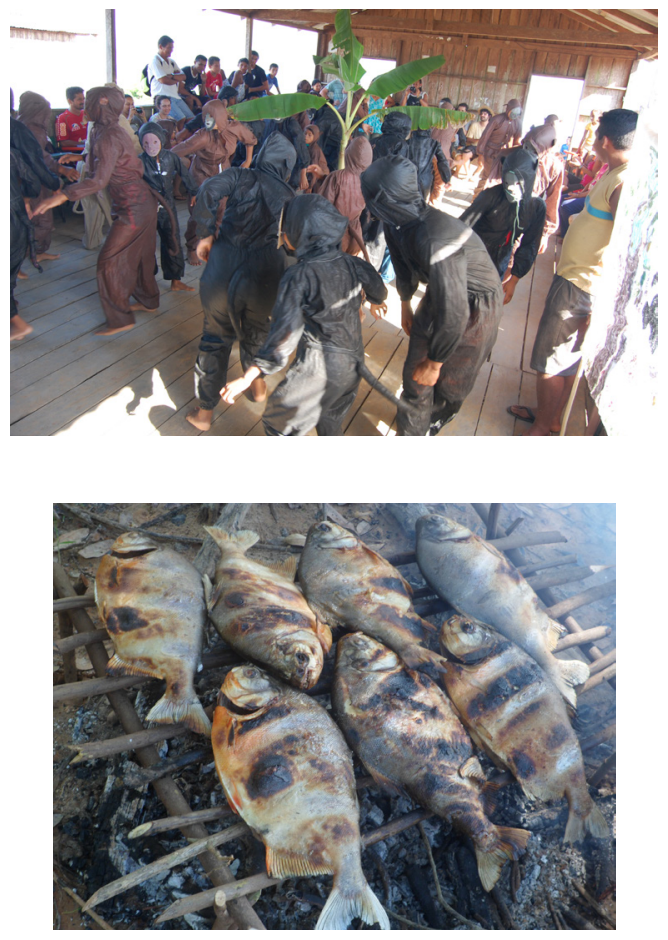

Dança dos macacos doidos mais acima e peixe assado na beira do rio.

\section{PÓS EXPEDIÇÕES}

Este projeto permitiu situações importantes na vida dos pesquisadores e dos envolvidos com o trabalho. A convivência de 20 dias, compartilhando um barco, almoçando, jantando e discutindo geografia dia e noite, pensando em alternativas e em possibilidades do trabalho no Amazonas ampliou nossa possibilidade de
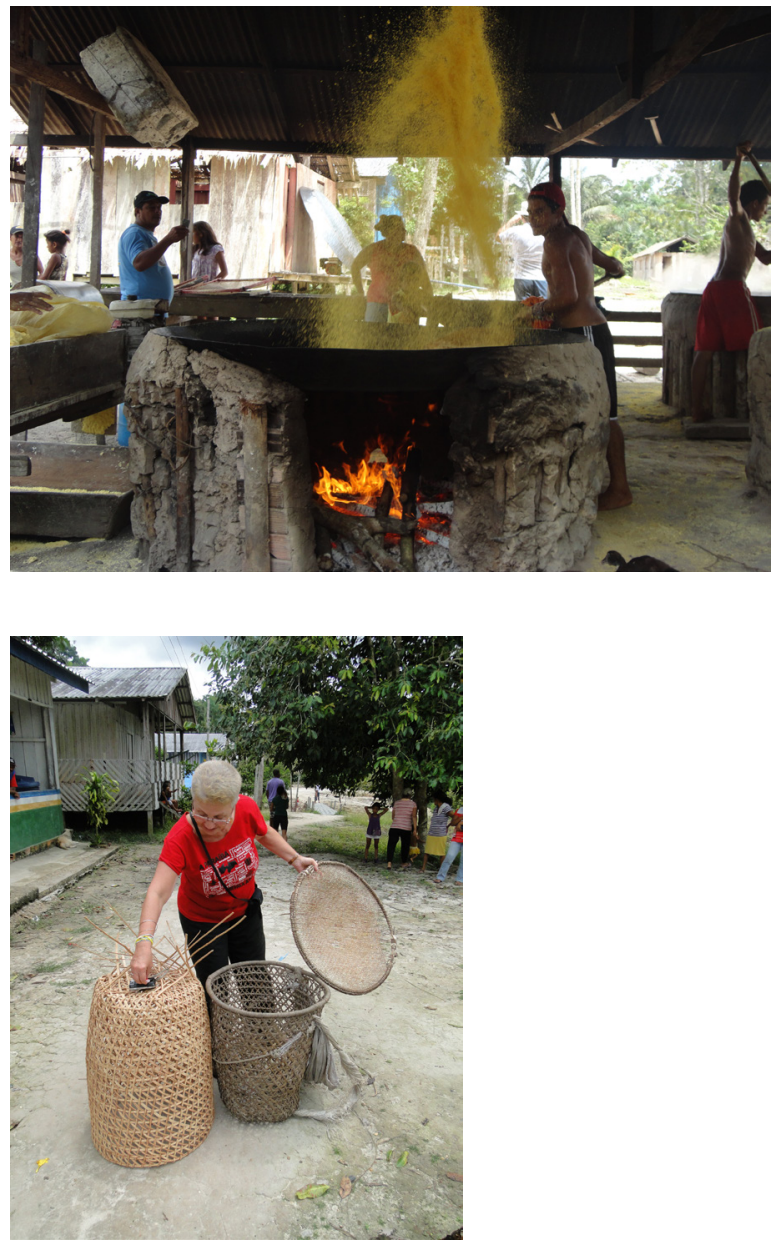

Produção da farinha e imagem do Paneiro e Peneira feitos de palha.

atuação, abriu novos caminhos, traçou novos rumos e aproximou-nos enquanto amigos. 0 violão e o pandeiro nos acompanharam na volta a Porto Alegre, pois aprendemos uma dimensão do trabalho geográfico que não apenas a formalidade, mas a descontração que gera aproximação na relação com as comunidades.

Esta vivência aprofundou, desmistificou, marcou o Amazonas em nossos corações e corpos. Permitiu abrir o caminho para futuros envolvimentos individuais e coletivos. Esta gestação está possibilitando o nascimento de um novo projeto, com outra forma de envolvimento, desta vez com a educação, guiada pela profundidade do carinho manifestado pelas crianças e pela necessidade de contribuir com o movimento em favor da educação, protagonizado pelos jovens e lideranças da FLONA.

\section{EU QUERO É PROTEGER}

Eu não sei de onde vem, Esse mal cheiro de poluição, Eu só sei que faz mal pra saúde e dói de ver no coração.

Tenho medo de ser tarde, e ver a floresta se acabar, e o jeito é ter peito e toda a floresta preservar. 
Eu to é abalado, nizados pela instituição à que pertencem. Grupo do tô gritando pro mundo, NEGA: Cláudia Luiza Zeferino Pires, Cleder Fontana, e não to nem ligando, Cristiano Quaresma de Paula, Cristina Kazakevi-

pro que vão dizer, cius, Daniele Machado Vieira, Dirce Maria Antunes conservar não é errado, Suertegaray,Elisa Delfino, Laurindo Antônio Guase se eu estiver enganado, que se danem tudo eu quero é proteger.

Heitor Mendonça Neto, jovem morador da FLONA de Tefé

Embora o texto acima tenha sido sistematizado por um dos pesquisadores, o grupo envolvido, efetivamente, neste projeto- Cartografia Social em Comunidades Ribeirinhas: Flona De Tefé - Amazonas,é bem maior. Assim segue a menção das pessoas sem as quais este trabalho não teria sido possível, orgaselli, Luiz Alberto Morelli, , Mateus G. Oliveira, Pedro Saldanha Frantz, Renato Barbieri, Sinthia Cristina Batista, Theo Soares De Lima. Grupo do ICMBIO/ Tefé: Astrogildo Martins de Moraes, Gabriella Calixto Scelza, Rafael Suertegaray Rossato.

Autor: Pablo Leandro Proença Ferreira

As imagens mostradas neste relato foram produzidas pela equipe que participou das etapas de mapeamento, acompanhados pelo ICMBio Tefé e por lideranças entre os próprios ribeirinhos. 